\title{
Sensitivity analysis of the seismic performance of ancient masonry buildings
}

\author{
Nuno Mendes ${ }^{1 *}$ and Paulo B. Lourenço ${ }^{1}$ \\ ${ }^{1}$ ISISE, Department of Civil Engineering, University of Minho \\ Azurém Campus, 4800-058, Guimarães, Portugal
}

\begin{abstract}
This paper presents a sensitivity analysis taking into account possible variations on the features of masonry buildings. The main objective of the analysis is to compare the seismic performance of a typology of buildings in Lisbon as a function of the changes of its properties with respect to a reference model calibrated from experimental tests. The sensitivity analysis was carried out using non-linear dynamic analysis with time integration and using pushover analysis proportional to the mass of the structure. The results show that the Young's modulus of the masonry walls, the Young's modulus of the timber floors and the compressive non-linear properties are the parameters that most influence the seismic performance of this type of tall and weak existing masonry structures. Furthermore, it is concluded that the stiffness of the timber floors significantly influence the strength capacity of the building and the type of collapse mechanism.
\end{abstract}

Keywords: Seismic performance; masonry; existing buildings; numerical analysis. 


\title{
Sensitivity analysis of the seismic performance of ancient masonry buildings
}

\author{
Nuno Mendes ${ }^{1 *}$ and Paulo B. Lourenço ${ }^{1}$ \\ ${ }^{1}$ ISISE, Department of Civil Engineering, University of Minho \\ Azurém Campus, 4800-058, Guimarães, Portugal
}

\begin{abstract}
This paper presents a sensitivity analysis taking into account possible variations on the features of masonry buildings. The main objective of the analysis is to compare the seismic performance of a typology of buildings in Lisbon as a function of the changes of its properties with respect to a reference model calibrated from experimental tests. The sensitivity analysis was carried out using non-linear dynamic analysis with time integration and using pushover analysis proportional to the mass of the structure. The results show that the Young's modulus of the masonry walls, the Young's modulus of the timber floors and the compressive non-linear properties are the parameters that most influence the seismic performance of this type of tall and weak existing masonry structures. Furthermore, it is concluded that the stiffness of the timber floors significantly influence the strength capacity of the building and the type of collapse mechanism.
\end{abstract}

Keywords: Seismic performance; masonry; existing buildings; numerical analysis.

\section{Introduction}

The seismic behaviour of ancient masonry buildings is particularly difficult to characterize and depends on several factors, such as the material properties, the geometry, the foundations, the connections between walls and floors, the connections between walls and roof, the stiffness of the horizontal diaphragms or the building 
condition. Furthermore, "non-structural" elements (partition walls) and their connection to the load-bearing walls can also contribute to the performance of these buildings.

Masonry is a composite material that consists of units and mortar, which has been used for construction of housing and many important monuments around the world. Units are such as bricks, blocks, ashlars, irregular stones and others. Mortar can be clay, bitumen, chalk, lime/cement based mortar, glue or other. The huge number of possible combinations generated by the geometry, nature and arrangement of units as well as the characteristics of the joints raises doubts about the accuracy of the term masonry to identify a single structural material.

The strength of masonry depends on the unit and mortar properties as well as on the construction technique. As an example, the compressive strength of stone units may range from values such as $5 \mathrm{MPa}$ (low quality limestone), and even less for tuff, to over $130 \mathrm{MPa}$ (good quality limestone), and even more for granite or marble. The strength of the mortar also presents large variations and depends on the proportion of its components (cement, lime, sand, soil and water) used in the mix [1]. The compressive strength of the mortar of ancient masonry buildings can be about 1.5-3.5 $\mathrm{MPa}[2,3]$, even is weaker and stronger mortars can be found. Furthermore, the strength and failure modes of masonry are dependent on the loading direction and combination of the loads [4]. Nevertheless, the mechanical behaviour of different types of masonry has some common features: high specific mass, low tensile strength, low to moderate shear strength and low ductility (quasi-brittle behaviour). The specific mass of stone masonry can range between $1700 \mathrm{~kg} / \mathrm{m}^{3}$ to $2200 \mathrm{~kg} / \mathrm{m}^{3}$ [5].

The characteristics of masonry make it a material mainly suitable for structural elements subjected to compressive stresses caused by vertical static loads, such as walls, arches, vaults and columns subject to the self-weight. Masonry properties have a direct 
influence on the seismic performance of unreinforced masonry buildings and massive damages have been observed in strong seismic events. The inertial forces induce tensile and shear stresses which may lead to the failure of masonry elements and, consequently, to local or global collapse of the building. Detailed information on the mechanical behaviour of the masonry is given in $[1,4,6]$.

The geometrical regularity in plan and in elevation as well as the structural simplicity (well distributed of mass and stiffness) improve the seismic performance of masonry structures, preventing local damage and decreasing torsional effects. These criteria, together with requirements for material properties in terms of strength and robustness, and rules for design and detailing are present in modern codes [7, 8, 9], aiming at a good seismic performance of masonry buildings in terms of strength capacity and adequate collapse mechanisms. But, existing masonry buildings often present geometric and material properties, which may lead to brittle or non-proportionated collapse mechanisms. The damage generally occurring in unreinforced masonry buildings due to the seismic action are cracks between walls and floors, cracks at the corners and at wall intersections, out-of-plane collapse of the perimetral walls, cracks in spandrels beams and/or parapets, diagonal cracks in structural walls, partial disintegration or collapse of structural walls and partial or complete collapse of the buildings [6]. For more information about the damage occurring in unreinforced masonry buildings, see e.g. $[10,11]$

The present work presents a sensitivity analysis taking into account variations of the features in ancient masonry buildings. The main objective of the sensitivity analysis is to compare the response of the structure as a function of the change of its properties with respect to the response of a reference numerical model, which was calibrated with 
an experimental test. The sensitivity analysis was carried out using non-linear dynamic analysis with time integration and pushover analysis proportional to the mass.

\section{Seismic performance of masonry walls and timber floors}

Although the seismic performance of unreinforced masonry buildings depends on several aspects, only the seismic behaviour of the masonry walls and of the floors are discussed here. The in-plane behaviour of masonry walls depends on the geometry of piers, spandrels and openings. In what concerns the seismic behaviour of piers, the typical in-plane collapse mechanisms (Fig. 1) are [12, 13]:

- Rocking induced by bending, which causes horizontal cracks at the top and at the bottom of the pier. The failure of the pier occurs by overturning of the wall;

- Sliding associated with horizontal forces at the piers that are larger than the shear strength of the bed joints (low vertical load and low friction coefficient), which is characterized by single full pier width horizontal cracks;

- Diagonal tension, in which the principal tensile stress caused by the seismic action exceeds the strength of masonry and diagonal cracks arise. The cracks can propagate along the bed and head joints or go through the units, depending on the strength of the mortar, mortar-unit interface and unit;

- Toe crushing, which can appear in combination with rocking or diagonal tension. The toes of the piers are usually zones of high compressive stresses and when the principal compressive stress caused by the seismic action exceeds the strength of the masonry, compressive failure (crushing) can occur. 


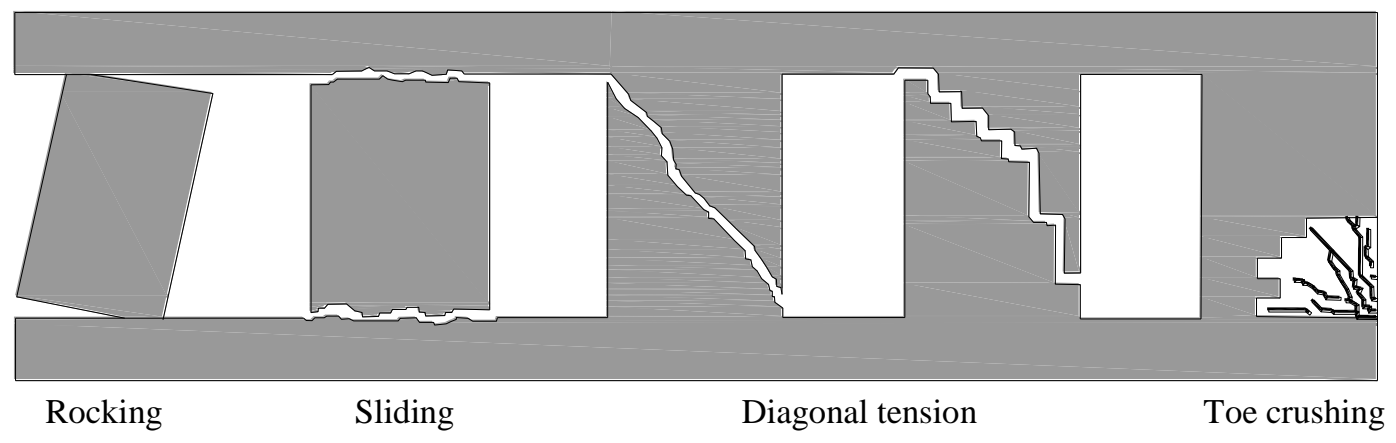

Fig. 1. In-plane collapse mechanisms of the piers (adapted from [13]).

The behaviour of spandrels is similar to the behaviour of piers. However, two aspects have to be taken into account: (a) the axis of the spandrel is horizontal and not vertical as in the piers; (b) the normal stress existing in the spandrels, caused by vertical loads, is much lower than the one in the piers. The first aspect is important for regular masonry, due to the orthotropic behaviour, while the behaviour of irregular masonry is more independent from the load direction. The second aspect has consequences in all types of masonry, as the normal stress has a strong influence on strength. Fig. 2a presents the in-plane behaviour of spandrels subjected to a seismic action, in which shear stresses occur and can lead to them to collapse (Fig. 2b). In masonry buildings with elements that prevent such collapse mechanisms (Fig. 2c), diagonal compression occurs and these elements increases the bending strength of the spandrels. Under these conditions, the spandrels present two possible collapse mechanisms [14]:

- Collapse due to high compression of diagonal struts (similar to the collapse of piers subjected to combined axial and bending forces);

- Collapse due to diagonal tension (shear failure). 


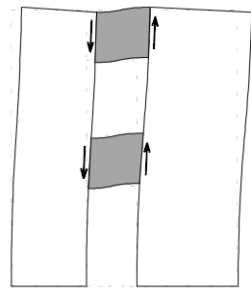

(a)

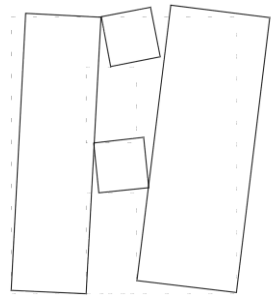

(b)

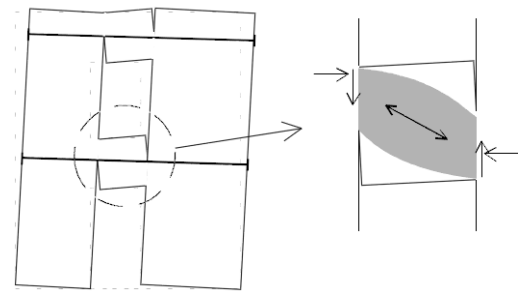

(c)

Fig. 2. In-plane behaviour of the spandrels [14].

The out-of-plane behaviour of unreinforced walls is rather complex and depends on the connection between walls and floors/roof, the connection between transverse and longitudinal walls, and the in-plane stiffness of the floors. When the floors are rigid and are adequately connected, masonry walls have local effects. On the other hand, when the floors are flexible or the connection between the walls and the floors is weak, the walls exhibit a global behaviour (independent of the floor levels) with collapses involving one or more floors and, consequently, have lower stiffness and strength [15]. Diaphragms distribute the inertial forces to the vertical resisting elements. This distribution depends on the in-plane stiffness of the diaphragms and on the connection between walls and diaphragms. In contrast to a rigid diaphragm, in which the distribution among the vertical elements is affected only by the location and lateral stiffness of these structural elements, a flexible diaphragm (timber floors) usually exhibits significant bending and shear deformations under horizontal loads, influencing the distribution of the load among the elements of the structure. Therefore, the flexibility of the floor diaphragms and of the connections between these and the masonry walls plays an important role in the global and local response of masonry buildings under seismic load. 


\section{Preparation of the reference numerical model}

The numerical model presented next is representative of a Portuguese masonry building typology - gaioleiro buildings [16] and is based on a mock-up tested in the 3D shaking table of the National Laboratory for Civil Engineering (LNEC) in Lisbon [17]. The mock-up has four floors, two facades with openings, two gable walls without openings, and timber floors. The timber floors is made of medium-density fibreboard (MDF) panels, with thickness equal to $0.012 \mathrm{~m}$, connected to a set of timber joists spanning in the direction of the shortest span. The reference numerical model (Fig. 3a) was prepared using the Finite Element Method (FEM) and the non-linear analysis software DIANA [18], in which quadratic shell elements with eight nodes (CQ40S) were used for simulating the masonry walls and beam elements with three nodes (CL18B) were used for simulating the MDF panels and the timber joists. All the finite elements are based on the theory of Mindlin-Reissner, in which the shear deformation is taken into account. In the modelling of the floors, shell elements were used aiming at simulating the in-plane deformability (Fig. 3b). The thickness of the masonry walls and of the MDF panels is equal to $0.510 \mathrm{~m}$ and $0.036 \mathrm{~m}$, respectively, and the dimensions of the cross section of the timber joists are equal to $0.300 \times 0.225 \mathrm{~m}^{2}$ (width and height), with spacing of 1.05 m. In plan, the numerical model has $9.45 \times 12.45 \mathrm{~m}^{2}$ and the interstory height is equal to $3.60 \mathrm{~m}$. The translation and rotation degrees of freedom at the base were restrained. In what concerns the connections, tyings providing equal translation of degrees of freedom between walls and floors were assumed. The numerical model involves 5,816 elements (1,080 beam elements and 4,736 shell elements) with 15,176 nodes, resulting in 75,880 degrees of freedom. 


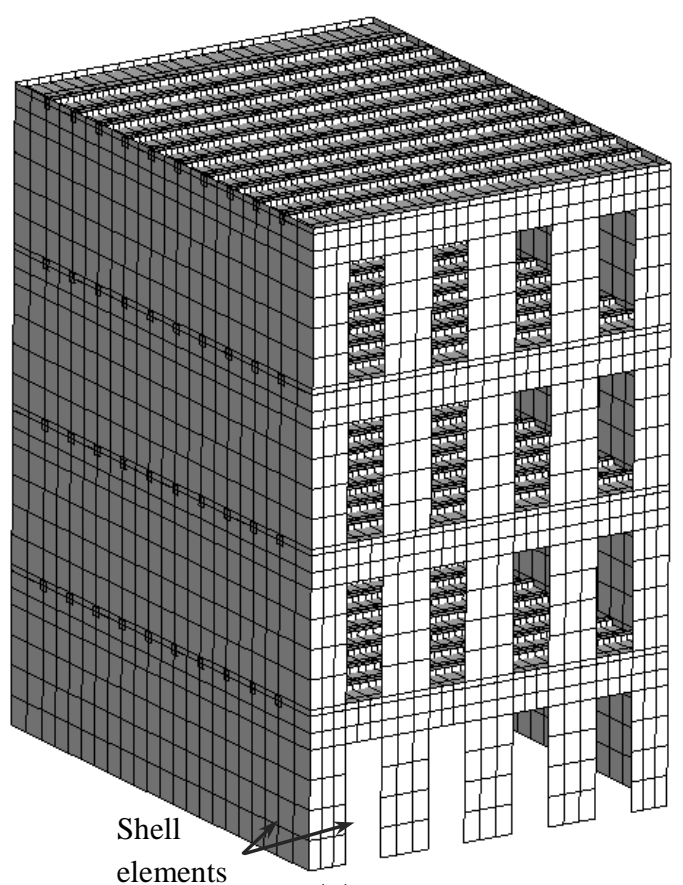

(a)

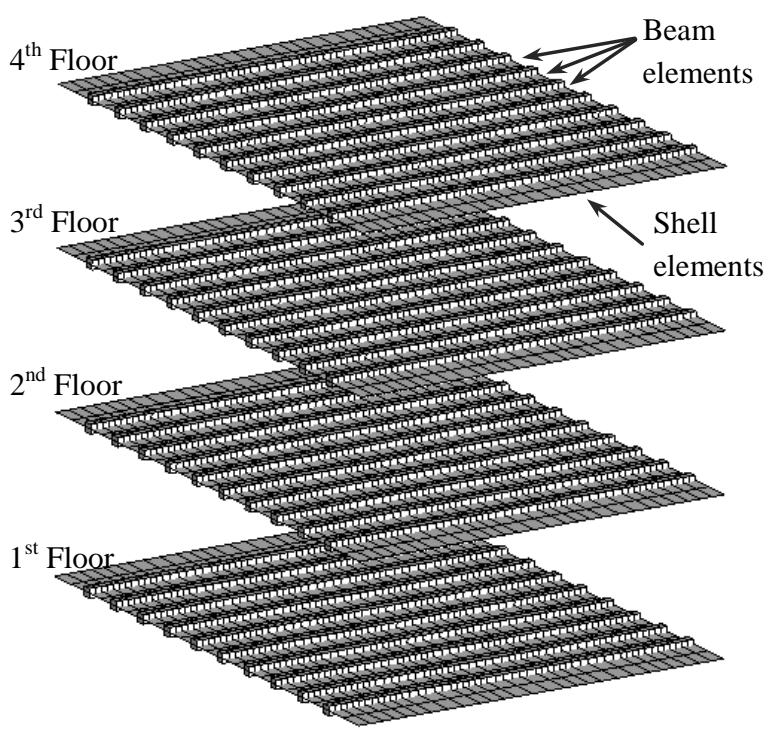

(b)

Fig. 3. Numerical model: (a) general view; (b) detail of the floors.

The selection of the masonry constitutive model was based on a compromise between accuracy of the results and computation time. The Total Strain Fixed Crack Model [18] assumes smeared cracks based on total strains and was selected due to its robustness and simplicity. In this model, the crack directions are fixed after the onset of cracking. The non-linear behaviour of the masonry was considered, assuming exponential softening for the tensile behaviour and parabolic hardening followed by softening for the compressive behaviour. The shear behaviour was simulated by a linear relationship between stress and strains, in which the shear stiffness is reduced after cracking according to the following equation:

$$
G^{c r}=\beta G
$$

where $G^{c r}$ is the shear modulus after cracking, $G$ is the elastic shear modulus and $\beta$ is the shear retention factor (ranging from zero to one). 
The crack bandwidth $h$ for the shell elements was estimated as function of the area of the element $A$, making the analysis results independent of the size of the finite element mesh:

$$
h=\sqrt{A}
$$

Table 1 and Table 2 present the linear and non-linear material properties of the reference numerical model, respectively. These have been obtained from modal updating of the experimental shaking table test, experimental data and recommendations, see [17] for details.

Table 1: Linear material properties for the reference model.

\begin{tabular}{cccc}
\hline & Young's modulus [GPa] & Specific mass $\left[\mathrm{kg} / \mathrm{m}^{3}\right]$ & Poisson ratio \\
\hline Masonry walls & 1.00 & 2160 & 0.2 \\
MDF panels & 0.16 & 760 & 0.3 \\
Timber joists & 12.00 & 580 & 0.3 \\
\hline
\end{tabular}

Table 2: Non-linear material properties of the masonry walls for the reference model.

\begin{tabular}{lcccc}
\hline & $\begin{array}{c}\text { Compressive } \\
\text { strength } \\
f_{c}[\mathrm{MPa}]\end{array}$ & $\begin{array}{c}\text { Compressive } \\
\text { fracture energy } \\
G_{c}[\mathrm{~N} / \mathrm{mm}]\end{array}$ & $\begin{array}{c}\text { Tensile } \\
\text { strength } \\
f_{t}[\mathrm{MPa}]\end{array}$ & $\begin{array}{c}\text { Mode I- tensile } \\
\text { fracture energy } \\
G_{t}[\mathrm{~N} / \mathrm{mm}]\end{array}$ \\
\hline Masonry walls & 1.00 & 1.60 & 0.10 & 0.05 \\
\hline
\end{tabular}

In what concerns damping for the non-linear dynamic analysis, the $\underline{C}$ viscous damping (proportional to the velocity) of Rayleigh was adopted, which is a linear combination between the mass and stiffness matrix in the form [19]:

$$
\underline{C}=\alpha \underline{M}+\underline{\beta} \underline{K}
$$

where $\alpha$ and $\beta$ are the coefficients that weigh the contribution of the mass $\underline{M}$ and $\underline{K}$ matrices, respectively. The values for $\alpha(1.48218)$ and $\beta(0.00052)$ were determined 
through the damping ratios identified in the dynamic identification tests carried out at LNEC [17].

\section{Seismic performance of the reference numerical model}

Non-linear dynamic analyses with time integration and pushover analyses proportional to the mass were carried out. In the dynamic analysis, two artificial accelerograms were applied in two uncorrelated orthogonal directions (Earthquake 100\%). The accelerograms were generated based on stochastic methods and techniques of finite fault modelling, with parameters adequate for Portugal [20] and duration equal to $30 \mathrm{~s}$ (intense phase). The response spectrum of the accelerograms is compatible with the type 1 design response spectrum defined by Eurocode 8 [7] and Portuguese National Annex for Lisbon $\left(P G A=1.5 \mathrm{~m} / \mathrm{s}^{2}\right)$, with a damping ratio equal to $5 \%$ and a type $A$ soil (rock, $S=1$ ). The pushover analysis is a non-linear static analysis that aims at simulating the structural response during an earthquake, through application of incremental horizontal forces (forced based) or displacements (displacement based) until collapse. The response of the structure is given by the so-called capacity curve, which represents the value of the base shear or seismic coefficient $\alpha_{b}$ (Eq. (4)) versus the displacement at a control point (usually at the top of the structure).

$$
a_{b}=\left(\sum\right. \text { Horizontal forces at the base)/(Self-weight of the structure) }
$$

In the non-linear dynamic analysis with Earthquake 100\%, the maximum seismic coefficient at the base is equal to 0.10 and 0.25 in the transversal and longitudinal direction, respectively (Fig. 4). According to the pushover analyses, the force based capacity reaches its limit in the transversal direction $\left(\alpha_{b}=0.10\right)$. However, in the longitudinal direction the seismic coefficient obtained from the non-linear dynamic 
analysis $\left(\alpha_{b}=0.25\right)$ is significantly lower than the force based capacity obtained from the pushover analysis $\left(\alpha_{b}=0.46\right)$. Furthermore, in this non-linear dynamic analysis the displacement is significantly lower than the value obtained from the pushover analysis. As an example, in the transversal direction the maximum displacement at the top obtained from the non-linear dynamic analysis (Earthquake 100\%) and from the pushover analysis is about $4.4 \mathrm{~cm}$ and $20.0 \mathrm{~cm}$, respectively. Thus, the seismic action was increased and a non-linear dynamic analysis with Earthquake 300\% was carried out, aiming at exploring the deformation capacity of the structure and obtaining serious damage that allows identifying clearly the collapse mechanism. In the non-linear dynamic analysis of the Earthquake $300 \%$ (Fig. 4), the force based capacity is close to the one obtained from the pushover analyses. In terms of deformation, in the transversal direction the non-linear dynamic analysis of the Earthquake $300 \%$ presents similar maximum displacement at the top. However, in the longitudinal direction the analyses present significant differences in terms of maximum displacement.

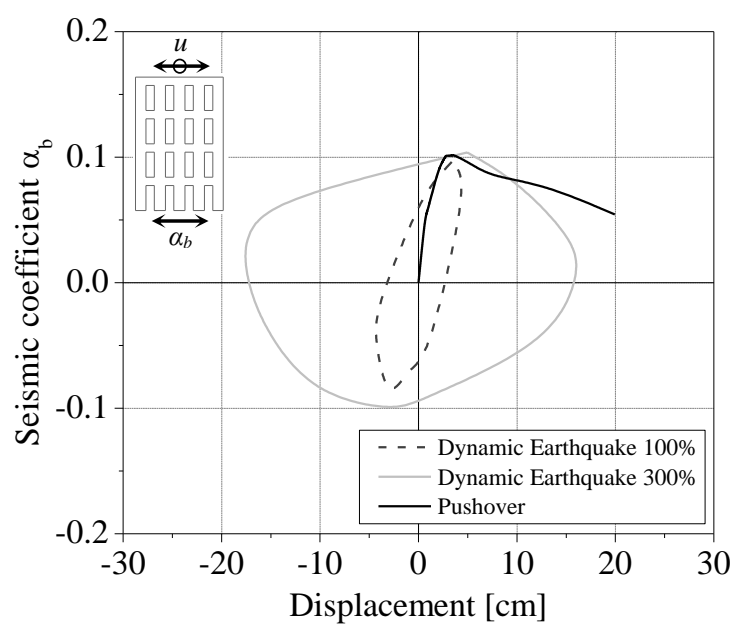

(a)

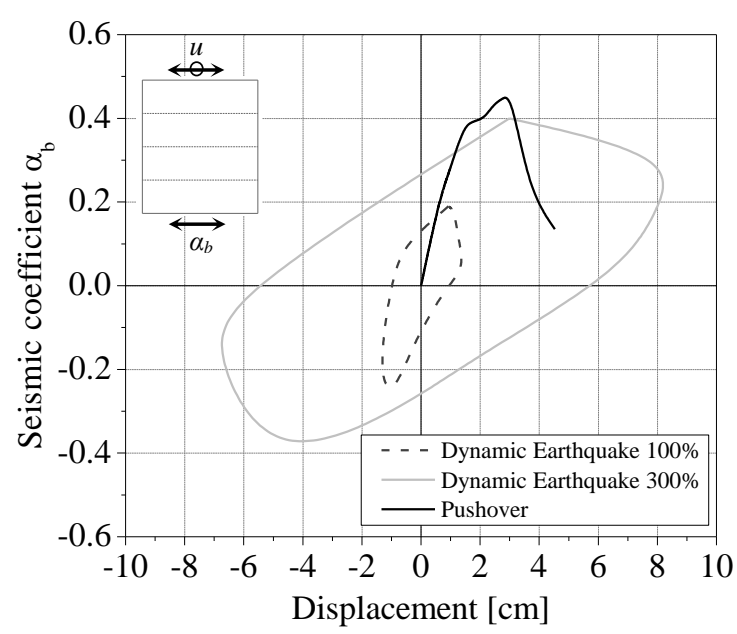

(b)

Fig. 4. Envelope of the response obtained from the non-linear dynamic analysis with time integration and capacity curve obtained from the pushover analysis of the reference model in the: (a) transversal direction; (b) longitudinal direction. 
Fig. 5a presents the distribution of the maximum principal tensile strains, which is an indicator of existing cracking, for the non-linear dynamic analysis of the Earthquake $100 \%$. It is observed that damage concentrates at the spandrels, due to the diagonal cracking, and at the piers of the top floor, due to in-plane rocking and out-of-plane bending. The gable walls do not present significant damage. In the Earthquake $300 \%$ (Fig. 5b) the structure presents serious damage, with several spandrels fully damaged and piers at the top floor presenting significant cracks due to in-plane rocking and outof-plane bending. Furthermore, the piers of the first floor also present severe damage, due to the failure of the spandrels and do not adequately restrict the relative displacements of the piers, leading to damage mainly due to in-plane forces. The gables walls also present damage, with shear cracks, originating at the floor levels and progressing through the walls, and a vertical cracks at the top of the building, dividing the building in two. Furthermore, important local damage at the base and at the connections between the gable walls and the joists of the first floor is observed, due to impact between joists and walls.

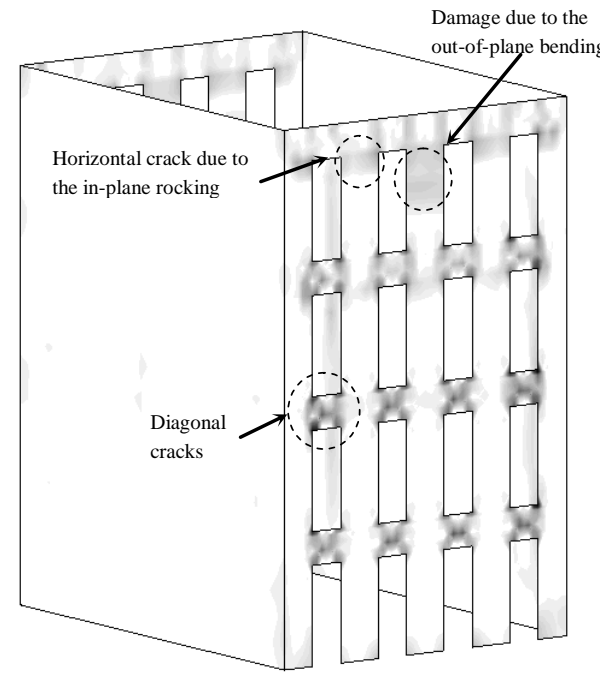

(a)

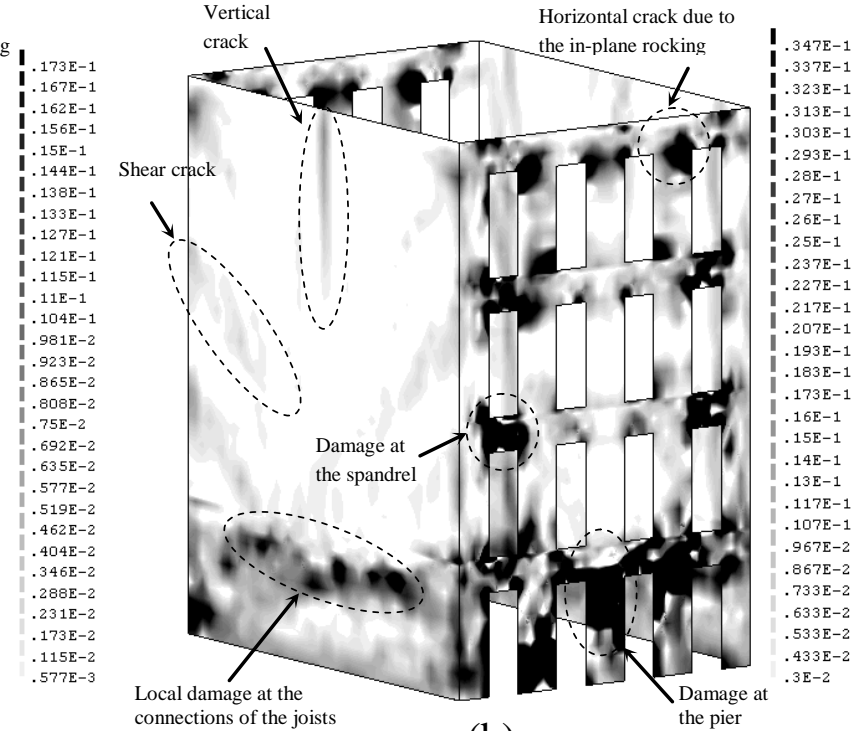

(b)

Fig. 5. Maximum tensile principal strains at the external surface of the non-linear dynamic analyses of the reference model: (a) Earthquake 100\%; (b) Earthquake $300 \%$. 
Fig. 6 presents the maximum principal strains obtained in the pushover analysis in the transversal and longitudinal direction. The transversal damage (Fig. 6a) is partly in agreement to the one observed in the non-linear dynamic analysis caused by the inplane forces (Fig. 5b), mainly with damage concentration at the piers and horizontal cracks at the piers of the top floor, even if with important local differences (damage is not uniform in the dynamic analysis). The piers of the first floor and the base also present damage, but less severe in comparison to the damage observed in the non-linear dynamic analysis. In the pushover analysis in the longitudinal direction (Fig. 6b) the piers of the top floor do not presents significant damage caused by the out-of-plane bending as observed in the non-linear dynamic analyses (Fig. 5). The damage concentrates mainly in the gable walls, with two vertical shear cracks that have origin at the floor levels and progress to the central part of the base, and one vertical crack. According to the pushover analysis, the numerical model presents a typical collapse mechanism, in which the facades collapse with the vertical cracks occurring at the top floors of the gable walls (near to first joist of the timber floors) and at the corner of the first floor. The MDF panels are rather flexible and are not able to transfer the inertial forces of the facades to the gables, resulting in out-of-plane collapse of the facades. This collapse mechanism is not observed in the non-linear dynamic analysis, even if the maximum capacity in the longitudinal direction was also found for the Earthquake $300 \%$.

These conclusions are in agreement with different simulations made for masonry buildings without box behaviour [21], where it is advocated that, in general, the capacity and failure mode of pushover analysis for these buildings is not in agreement with experimental testing and time history analysis. 


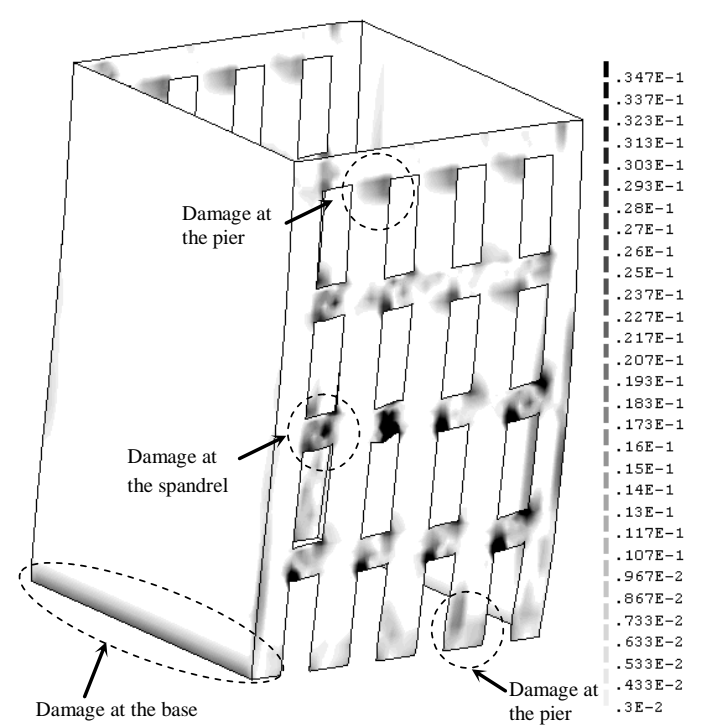

(a)

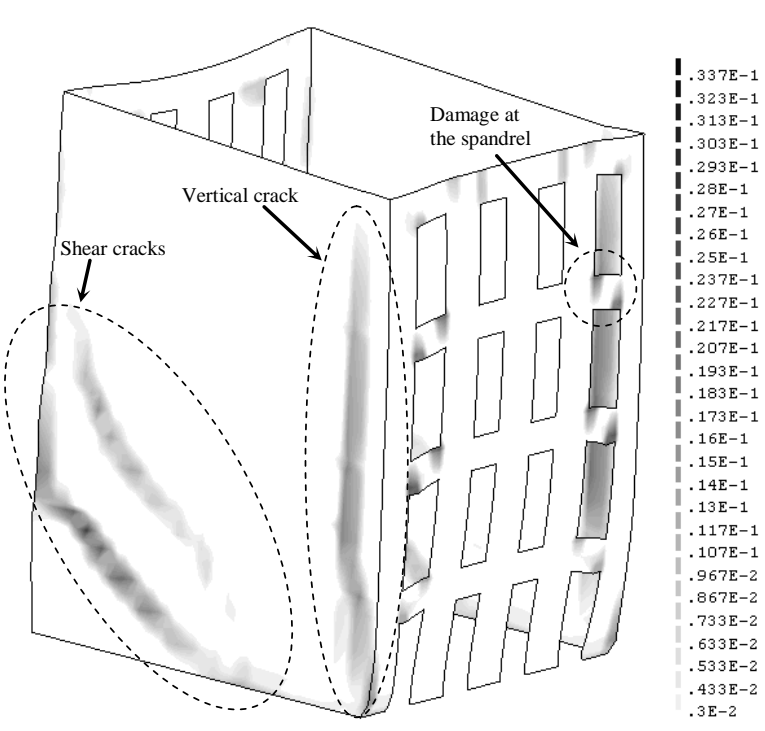

(b)

Fig. 6. Maximum tensile principal strains at the external surface of the pushover analysis of the reference model in the: (a) transversal direction;

(b) longitudinal direction.

\section{Non-linear dynamic sensitivity analysis}

Non-linear analysis involves several parameters that can influence the response to some extent and, consequently, can also influence the conclusions about the seismic performance of existing masonry structures. Thus, a sensitivity analysis was carried out, by changing the value of the different parameters with respect to the reference model, taking into account the dispersion in the features of the "gaioleiro" building typology. The parameters considered (Table 3) are the stiffness of the masonry walls, the stiffness of the floors, the non-linear properties of the masonry in compression and tension, and the damping ratio. The reference parameters were divided and multiplied by 2 , which is considered a rather large variation, with the exception of the damping ratio and the stiffness of the floors. For the damping ratio, round values considered in the code are adopted $(2 \%$ and $5 \%)$. The stiffness of the floors can vary to great extent due to the material adopted and the efficiency of the connections, and the reference values were divided and multiplied by 10 . Furthermore, the influence in the response of the vertical 
component of the earthquake was also studied. Next, the main results of the non-linear dynamic sensitivity analysis (Earthquake 300\%) are presented.

Table 3: Parameters considered in the dynamic sensitivity analysis.

\begin{tabular}{|c|c|c|c|}
\hline & Lower value & Reference value & Upper value \\
\hline Young's modulus of the walls & $0.5 \mathrm{x} E_{\text {walls,ref }}$ & $E_{\text {walls,ref }}=1.00 \mathrm{GPa}$ & $2.0 \mathrm{x} E_{\text {walls, ref }}$ \\
\hline Young's modulus of the floors & $0.1 \times E_{\text {floors }, \text { ref }}$ & $E_{\text {floors, ref }}=0.16 \mathrm{GPa}$ & $10 x E_{\text {floors, ref }}$ \\
\hline Compressive strength & $0.5 \times f_{c, r e f}$ & $f_{c, r e f}=1.00 \mathrm{MPa}$ & $2.0 \mathrm{x} f_{c, r e f}$ \\
\hline Compressive fracture energy & $0.5 \times G_{c, r e f}$ & $G_{c, r e f}=1.00 \mathrm{~N} / \mathrm{mm}$ & $2.0 \times G_{c, r e f}$ \\
\hline Tensile strength & $0.5 \times f_{t, r e f}$ & $f_{t, r e f}=0.10 \mathrm{MPa}$ & $2.0 \mathrm{x} f_{t, r e f}$ \\
\hline Tensile fracture energy & $0.5 \times G_{t, r e f}$ & $G_{t, r e f}=0.05 \mathrm{~N} / \mathrm{mm}$ & $2.0 \mathrm{x} G_{t, r e f}$ \\
\hline Damping ratio & $\zeta_{\text {Lower }}=2.0 \%$ & $\zeta_{\text {ref }}=3.3 \%$ & $\zeta_{\text {Upper }}=5.0 \%$ \\
\hline
\end{tabular}

The sensitivity analysis shows that the Young's modulus of the masonry walls, the Young's modulus of the timber floors and the compressive non-linear properties are the parameters that most influence the seismic performance of this type of structures. The maximum seismic coefficient varies about $50 \%$ with respect to the reference value when the Young's modulus of the masonry walls is changed. The stiffness of the floors has also an important role in the seismic performance of the structure. The numerical model with very flexible floor presents the typical out-of-plane collapse of the gable walls and damage at the corners. When the stiffness of the floors is increased the damage concentrates at the facades, mainly associated to in-plane forces (Fig. 7).

It is expected that the variation of compressive non-linear properties has limited influence in the response of masonry structures, but here a significant influence in the strength capacity of the structure has been found (Fig.8). This is due to the low reference value of the compressive strength and the type of failure mode obtained, given the considerable height of the buildings. Still, it is noted that the maximum compressive stress due to the self-weight is about $20 \%$ of the compressive strength, which would seem reasonable for the stability against vertical loading. 


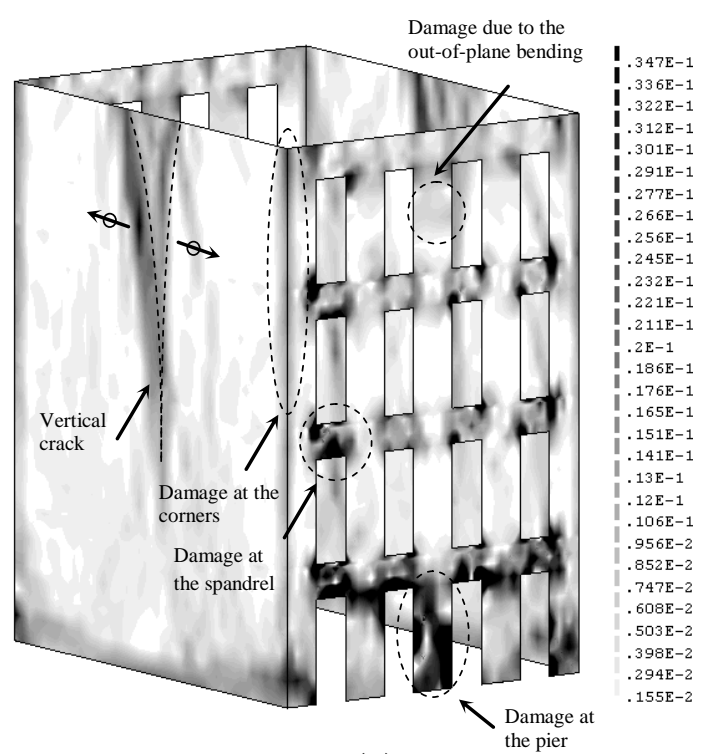

(a)

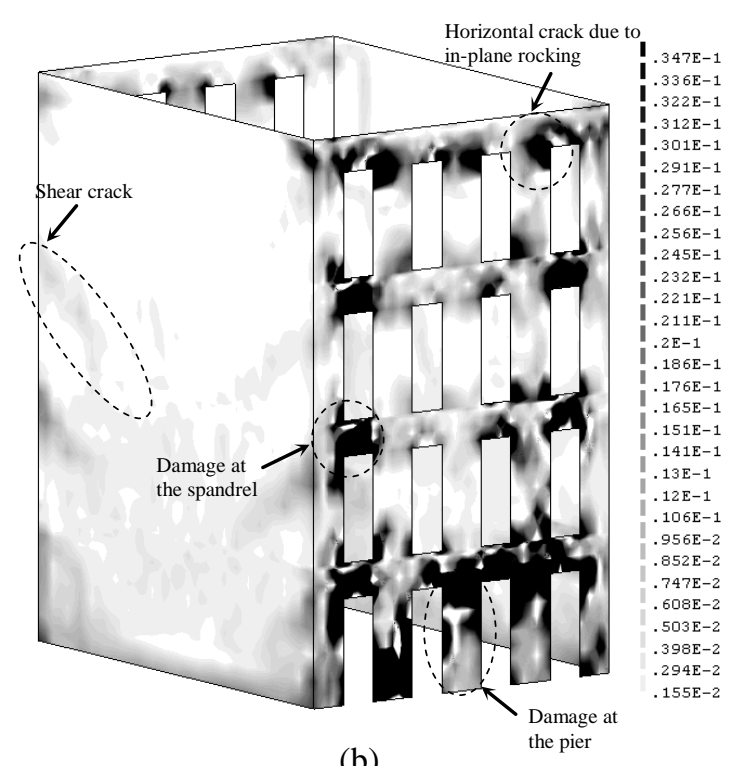

(b)

Fig. 7. Maximum tensile principal strains at the external surface, obtained from the dynamic analysis, varying the Young's modulus of the floors: (a) $0.1 \times E_{f l o o r s, r e f}$;

(b) $10 x E_{\text {floors, ref. }}$

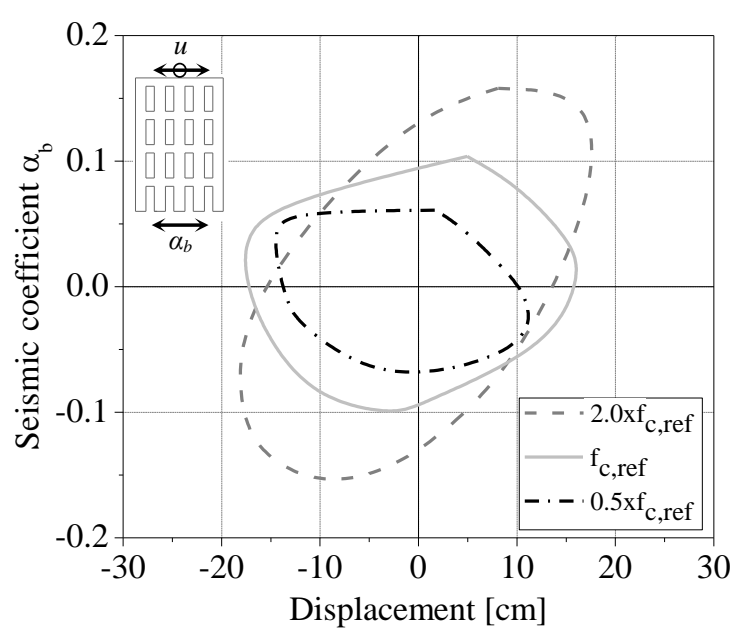

(a)

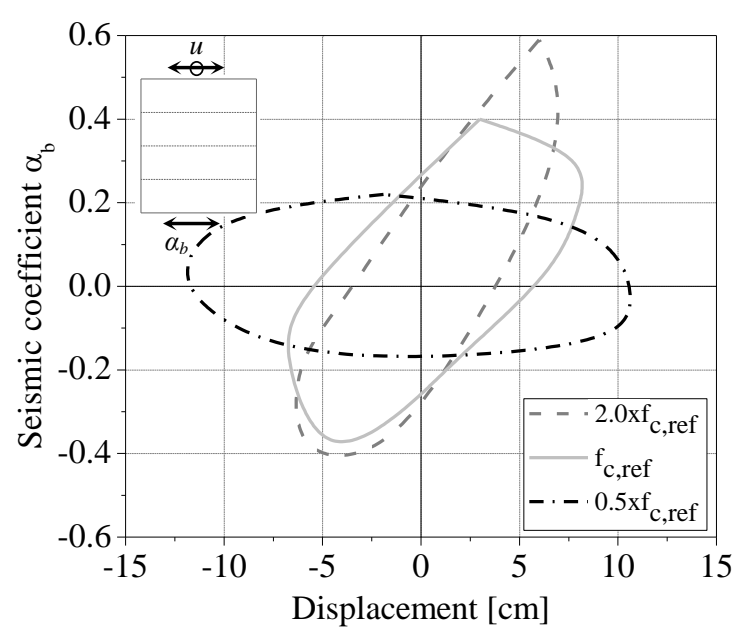

(b)

Fig.8. Envelope of the response varying the compressive strength in the: (a) transversal direction; (b) longitudinal direction.

The response exhibited small variations when the tensile properties were changed. The limits considered for the material properties correspond to a common feature of masonry - low tensile strength and a quasi-brittle behaviour, meaning that the nonlinear tensile properties do not to affect significantly the response under high seismic amplitudes. 
The response of the structure in the transversal direction does not change significantly decreasing the ratio damping of about $1 \%\left(\zeta_{\text {Lower }}=2.0 \%\right)$. The maximum variation of the response in the longitudinal direction with $\zeta_{\text {Lower }}=2.0 \%$ is equal to $-8 \%$ (displacement at the top). In the transversal direction with $\zeta_{\text {Upper }}=5.0 \%$ the maximum seismic coefficient increases about $10 \%$ and the maximum displacement at the top decreases about $17 \%$. In the longitudinal direction the response $\left(\zeta_{\text {Upper }}=5.0 \%\right)$ presents a variation of about $20 \%$ for both parameters. The numerical model with $\zeta_{\text {Lower }}=2.0 \%$ presents serious damage at the spandrels, piers at the top floor and at the base, and at the first floor of the gable walls. On the other hand, when increasing the damping $\left(\zeta_{\text {Upper }}=5.0 \%\right)$ the numerical model presents, as expected, a damage reduction. Still, these changes in response are reasonable for engineering applications.

The vertical component of the earthquake does not have an influence on the response because the compressive stresses present minimize the effect of the vertical acceleration. Furthermore, the structure is very stiff in the vertical direction and, consequently, presented very small displacements in this direction.

Tables 4 and 5 present the variation of the maximum seismic coefficient and displacement at the top of the structure obtained from the non-linear dynamic sensitivity analysis for the transversal direction (direction with the lowest strength capacity), where values larger than $25 \%$ are highlighted. It is considered that the analysis is oversensitive to the Young's modulus and the masonry compressive strength.

Table 4: Variation of the response in the transversal direction obtained from the dynamic sensitivity analysis for the lower limits of the parameters.

\begin{tabular}{cccccccc} 
& $0.5 \times E_{\text {walls,ref }}$ & $0.1 \times E_{\text {floors }, \text { ref }}$ & $0.5 \times f_{c, \text { ref }}$ & $0.5 \times G_{c, \text { ref }}$ & $0.5 \times f_{t, \text { ref }}$ & $0.5 \times G_{t, \text { ref }}$ & $\zeta=2 \%$ \\
\hline Seismic coefficient & $-10 \%$ & $10 \%$ & $-20 \%$ & $0 \%$ & $-2 \%$ & $10 \%$ & $0 \%$ \\
Displacement & $-7 \%$ & $24 \%$ & $-16 \%$ & $-11 \%$ & $4 \%$ & $-1 \%$ & $0 \%$
\end{tabular}


Table 5: Variation of the response in the transversal direction obtained from the dynamic sensitivity analysis for the upper limits of the parameters and earthquake vertical component.

\begin{tabular}{ccccccccc}
\cline { 2 - 8 } & $2.0 \times E_{\text {walls }, \text { ref }}$ & $10 \times E_{f l o o r s, r e f}$ & $2.0 \times f_{c, \text { ref }}$ & $2.0 \times G_{c, \text { ref }}$ & $2.0 \times f_{t, \text { ref }}$ & $2.0 \times G_{t, \text { ref }}$ & $\zeta=5 \%$ & $\begin{array}{c}\text { Vertical } \\
\text { earthquake }\end{array}$ \\
\hline Seismic coefficient & $39 \%$ & $20 \%$ & $70 \%$ & $20 \%$ & $20 \%$ & $10 \%$ & $10 \%$ & $10 \%$ \\
Displacement & $-17 \%$ & $-6 \%$ & $3 \%$ & $3 \%$ & $0 \%$ & $-4 \%$ & $-17 \%$ & $-3 \%$ \\
\hline
\end{tabular}

\section{Pushover sensitivity analysis}

As previously done for the non-linear dynamic sensitivity analysis, a pushover sensitivity analysis is presented next considering the same variations for the material parameters. Furthermore, the type of load pattern applied horizontally to the structure was also discussed and a pushover analysis proportional to the modal displacements of the first mode in the applied direction was carried out besides a uniform load distribution (Table 6). Here, the objective is to evaluate the response of the structure under a seismic action based on displacement (first mode proportional) with respect to a loading based in force (proportional to the mass). Note that according to [21], a uniform load distribution is recommended for a force based pushover analysis in historical buildings. Next, the most relevant variations of the response are presented.

Table 6: Parameters considered in pushover sensitivity analysis.

\begin{tabular}{|c|c|c|c|}
\hline & Lower value & Reference value & Upper value \\
\hline Young's modulus of the walls & $0.5 \times E_{\text {walls }, \text { ref }}$ & $E_{\text {walls,ref }}=1.00 \mathrm{GPa}$ & $2.0 \mathrm{x} E_{\text {walls, ref }}$ \\
\hline Young's modulus of the floors & $0.1 \times E_{\text {floors, ref }}$ & $E_{\text {floors, ref }}=0.16 \mathrm{GPa}$ & $10 \mathrm{x} E_{\text {floors }, \text { ref }}$ \\
\hline Compressive strength & $0.5 \mathrm{x} f_{c, r e f}$ & $f_{c, r e f}=1.00 \mathrm{MPa}$ & $2.0 \mathrm{x} f_{c, r e f}$ \\
\hline Compressive fracture energy & $0.5 \times G_{c, r e f}$ & $G_{c, r e f}=1.00 \mathrm{~N} / \mathrm{mm}$ & $2.0 \times G_{c, r e f}$ \\
\hline Tensile strength & $0.5 \times f_{t, r e f}$ & $f_{t, r e f}=0.10 \mathrm{MPa}$ & $2.0 \mathrm{x} f_{t, r e f}$ \\
\hline Tensile fracture energy & $0.5 \mathrm{x} G_{t, r e f}$ & $G_{t, r e f}=0.05 \mathrm{~N} / \mathrm{mm}$ & $2.0 \times G_{t, r e f}$ \\
\hline
\end{tabular}

The sensitivity analysis confirms that the Young's modulus of the masonry walls, the stiffness of the timber floors and the compressive strength have the highest influence on 
the strength capacity of the structure. The decrease of the tensile strength causes also a significant decrease of the strength capacity in the longitudinal direction $(-20 \%)$. In the pushover analysis in the transversal direction (direction with the lowest strength capacity) the damage is caused by in-plane forces at the facades and is similar to the one obtained from the non-linear dynamic analysis, in which severe damage at the spandrels and piers is found.

In the pushover analysis with varying Young's modulus of the timber floors, the maximum seismic coefficient presents variations of about $12 \%$ (Fig. 9). The major differences occur in the pushover analysis in the longitudinal direction, which is more dependent of the stiffness of the timber floors. The numerical model with $10 x E_{\text {floors, }}$ ef presents a response stiffer than the reference model and with a high reduction of the lateral forces after post-peak for low deformation (more brittle behaviour). On the other hand, the response of the numerical model with $0.1 \times E_{\text {floors, ref }}$ presents several loss of stiffness until the maximum seismic coefficient and high deformation (Fig. 9b). In the end of the pushover analyses in the longitudinal direction the numerical models with $0.1 \times E_{\text {floors, ref }}$ and $10 \mathrm{x} E_{\text {floors, ref }}$ present similar seismic coefficient and significantly different displacements. This is due to the serious damage in the numerical model with $0.1 \mathrm{x} E_{f l o o r s, r e}$, mainly due to the vertical crack near the corners, which causes the out-ofplane collapse of the facades (Fig. 10a). In the numerical model with $10 x E_{\text {floors, }}$ ref collapse occurs due to shear failure of the gable walls (Fig. 10b).

Finally, the pushover analysis proportional to the modal displacements of the first mode presents lower strength capacity with respect to the pushover analysis proportional to mass, and does not provide any improvement in the simulation of the local damage at the piers of the top floor caused by the out-of-plane bending. 


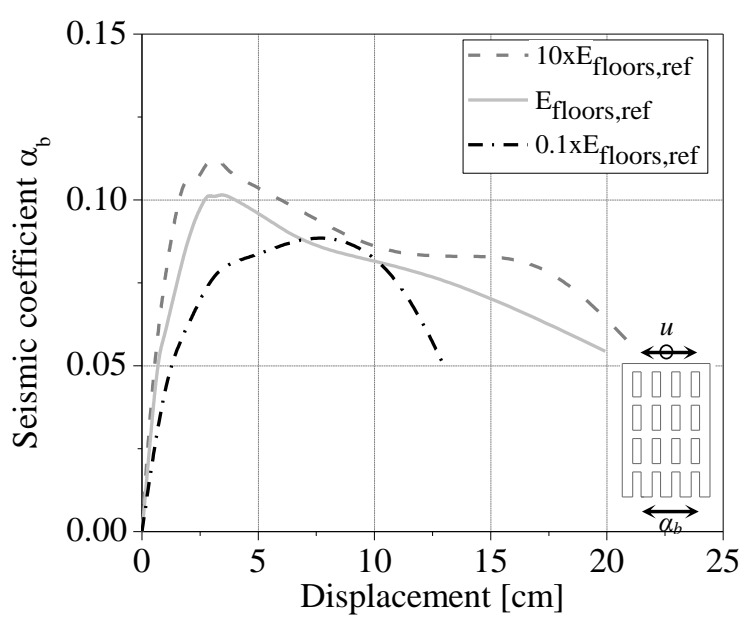

(a)

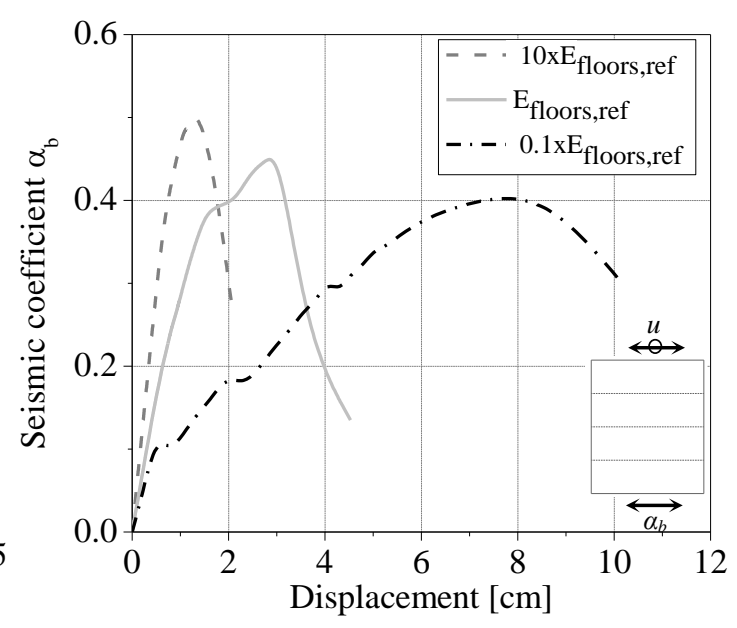

(b)

Fig. 9. Capacity curves varying the Young's modulus of the timber floors in the: (a) transversal direction; (b) longitudinal direction.

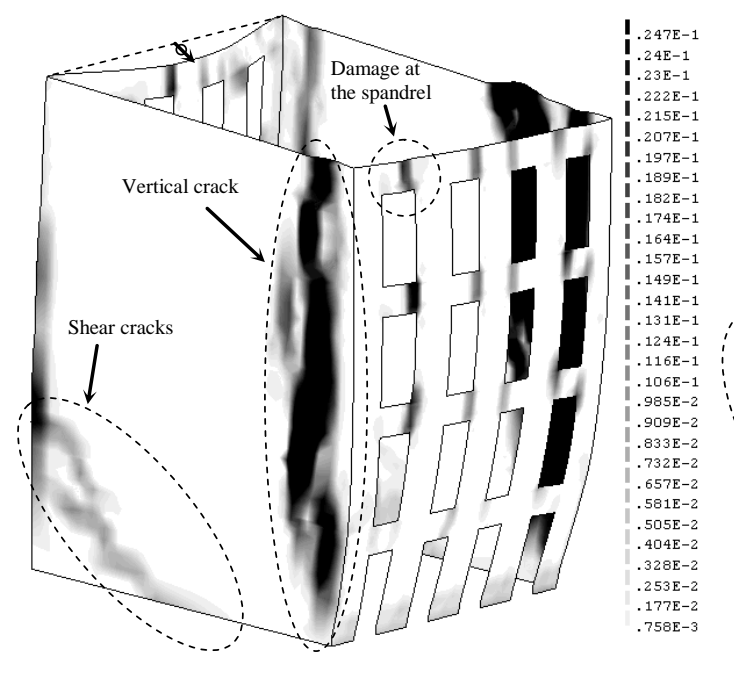

(a)

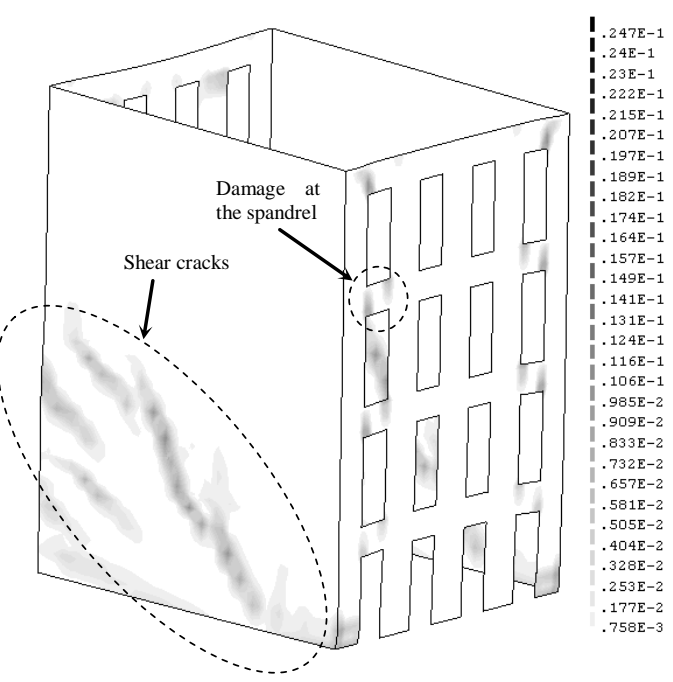

(b)

Fig. 10. Maximum tensile principal strains at the external surface, obtained from the pushover analysis in the longitudinal direction, varying the Young's modulus of the floors: (a) $0.1 \times E_{\text {floors, ref }}$; (b) $10 x E_{\text {floors }, \text { ref. }}$.

Again, Tables 7 and 8 present the variations of the maximum seismic coefficient obtained from the pushover sensitivity analysis for the transversal and longitudinal directions, where values larger than $25 \%$ are highlighted. It is considered that the analysis is oversensitive to the Young's modulus and the masonry compressive strength, which is exactly the same conclusion of the dynamic analysis. Still, the extreme 
variation found for the compressive strength in the dynamic analysis (up to $70 \%$ of the reference value) was not replicated by the pushover analysis.

Table 7: Variation of the maximum seismic coefficient obtained from the pushover sensitivity analysis for the lower limits of the parameters.

\begin{tabular}{ccccccc}
\hline Direction & $0.5 \times E_{\text {walls,ref }}$ & $0.1 \times E_{\text {floors, ref }}$ & $0.5 \times f_{c, r e f}$ & $0.5 \times G_{c, r e f}$ & $0.5 \times f_{t, r e f}$ & $0.5 \times G_{t, r e f}$ \\
\hline Transversal & $-2 \%$ & $-10 \%$ & $-32 \%$ & $-3 \%$ & $-2 \%$ & $-6 \%$ \\
Longitudinal & $-9 \%$ & $-14 \%$ & $-37 \%$ & $-7 \%$ & $-20 \%$ & $-6 \%$ \\
\hline
\end{tabular}

Table 8: Variation of the maximum seismic coefficient obtained from the pushover sensitivity analysis for the upper limits of the parameters and pushover analysis proportional to the first mode.

\begin{tabular}{cccccccc}
\hline Direction & $2.0 \times E_{\text {walls }, \text { ref }}$ & $10 \times E_{\text {floors,ref }}$ & $2.0 \times f_{c, \text { ref }}$ & $2.0 \times G_{c, \text { ref }}$ & $2.0 \times f_{t, r e f}$ & $2.0 \times G_{t, r e f}$ & $1^{\text {st }}$ Mode \\
\hline Transversal & $25 \%$ & $11 \%$ & $34 \%$ & $13 \%$ & $11 \%$ & $8 \%$ & $-12 \%$ \\
Longitudinal & $11 \%$ & $12 \%$ & $8 \%$ & $1 \%$ & $8 \%$ & $11 \%$ & $-27 \%$ \\
\hline
\end{tabular}

\section{Conclusions}

A sensitivity analysis using two techniques of structural modelling was carried out, namely: (a) non-linear dynamic analysis with time integration; (b) pushover analysis proportional to the mass. The objective was to evaluate the variation of the response taking into account the deviations in the main features of an ancient masonry building typology of the housing stock of Portugal with reasonable height (4 to 6 storeys) gaioleiro buildings. The Young's modulus of the masonry walls, Young's modulus of the timber floors, the compressive and tensile non-linear properties (strength and fracture energy) were the parameters considered in both sensitivity analyses. The influence of viscous damping and the vertical component of the earthquake was also considered in the non-linear dynamic analysis. Finally, a pushover analysis proportional to the modal displacement of the first mode in each direction was also carried out.

The non-linear dynamic analysis with time integration of the reference model with the Earthquake $100 \%$ shows that the structure reaches its strength capacity in the transversal direction for a seismic coefficient equal to 0.10 , which is according to the results obtained from the pushover analysis in the transversal direction. However, in the 
Earthquake $100 \%$ the deformation is moderate and the seismic amplitude was increased three times (Earthquake 300\%) for the sensitivity analysis through non-linear dynamic analysis, aiming at exploring the deformation capacity of the structure and at clearly identifying the collapse mechanisms. In the analysis with the Earthquake $300 \%$ the structure presents serious damage at the spandrels due to diagonal cracking and at the piers of the top floors due to the in-plane rocking and out-of-plane bending, indicating that collapse has been found. Furthermore, the piers of the first floor also present serious damage associated to the failure of the spandrels due to the in-plane forces. The gable walls presents shear cracks, a vertical crack at the top and local damage at the connections between masonry wall and timber floor of the first floor. The pushover analysis in the transversal direction is able to simulate only the damage at the facades caused by in-plane forces, namely the damage at the spandrels and at the piers. The capacity and failure mode obtained from pushover analysis in the longitudinal direction are in agreement with the results of the dynamic analysis.

The sensitivity analysis shows that, for this building typology, the results are oversensitive to the Young's modulus and compressive strength of the masonry walls for either dynamic time integration or pushover analyses. The Young's modulus of the timber floors, representing also the connections between floors and walls, also has some influence in the response, either in strength and collapse mechanism. The vertical component of the earthquake does not have any influence on the response of the numerical model, which is due to the high compressive stresses caused by self-weight and high stiffness in the vertical direction. The pushover analysis proportional to the modal displacements of the first mode presents a lower strength capacity with respect to the pushover analysis proportional to the mass, and does not provide a better agreement with the failure mode from the dynamic analysis. 


\section{Acknowledgement}

The first author acknowledges the financial support from the Portuguese Foundation for Science and Technology (FCT) through grant SFRH/BD/32190/2006.

\section{References}

[1] Paulay T, Priestley M. Seismic design of reinforced concrete and masonry buildings. John Wiley \& Sons Inc; 1992.

[2] Toumbakari E. Lime-pozzolan-cement grouts and their structural effects on composite masonry walls. PhD Thesis, Katholieke Universiteit Leuven, Belgium; 2002. [3] Valluzi M, Porto F, Modena C. Behaviour and modelling of strengthened three-leaf stone masonry walls. Materials and Structures 2004; 37, 3:184-192. (doi:10.1007/BF02481618)

[4] Lourenço PB. Computational strategies for masonry structures. PhD Thesis, Delft University of Technology, Netherlands; 1996. (Available from: http://www.civil.uminho.pt/masonry)

[5] Pinho F. Walls from ancient Portuguese buildings. "Edifícios", No8, National Laboratory for Civil Engineering, Lisbon, Portugal; 2000. (In Portuguese)

[6] Tomaževič M. Earthquake-resistance design of masonry buildings. Series on Innovation in Structures and Construction 1999; Vol. 1. Imperial College Press.

[7] EN 1998-1. Eurocode 8: Design of structures for earthquake resistance - General rules, seismic actions and rules for building. European Committee for Standardization; 2004.

[8] FEMA 440. Improvement of nonlinear static seismic analysis procedures. Applied Technology Council (ATC-55 Project), Department of Homeland Security, Federal Emergency Management Agency, Washington D.C; 2005.

[9] OPCM 3274. First elements on general criteria for seismic classification of the national territory and technical standards for construction in seismic areas. Ordinance of the President of the Council of Ministers; 2003. (In Italian)

[10] Bothara J, Brzev S. A tutorial: Improving the seismic performance of stone masonry buildings. $1^{\text {st }}$ ed. Earthquake Engineering Research Institute; 2011. (ISBN: 978-1-932884-48-7) 
[11] Carocci C. Guidelines for the safety and preservation of historical centres in seismic areas. Historical Constructions: Possibilities of numerical and experimental techniques, Guimarães, Portugal; 2001, p. 145-166.

[12] Magenes G, Calvi G. In-plane seismic response of brick masonry walls. Earthquake Engineering and Structural Dynamics 1997; 26, Issue 11: 1091-1112. (doi:10.1002/(SICI)1096-9845(199711)26:11<1091::AIDEQE693>3.0.CO;2-6).

[13] Yi T. Experimental investigations and numerical simulation of an unreinforced Masonry structure with flexible diaphragms. PhD Thesis, Georgia Institute of Technology; 2004.

[14] Magenes G, Bolognini D, Braggio C. Simplified methods for non-linear seismic of masonry buildings. National Group for Earthquakes Protection (GNDT); 2000. (In Italian)

[15] Candeias P. Seismic vulnerability assessment of ancient buildings. PhD Thesis, University of Minho, Portugal; 2008. (Available from: http://hdl.handle.net/1822/9057) (In Portuguese)

[16] Appleton J. Rehabilitation of "gaioleiros" buildings - a block in Lisbon. Orion edition; 2005. (ISBN: 9728620055) (In Portuguese).

[17] Mendes N, Lourenço PB, Campos-Costa A. Seismic vulnerability assessment of ancient masonry building an experimental method. Advanced Materials Research; 2010 133-134: 635-640. (doi: 10.4028/www.scientific.net/AMR.133-134.635).

[18] TNO. DIsplacement method ANAlyser. User's Manual, Release 9.4, Netherlands; 2009.

[19] Chopra A. Dynamics of Structures: Theory and applications to earthquake engineering. $3^{\text {rd }}$ ed. Prentice Hall; 2001.

[20] Carvalho A. Stochastic modelling of the seismic action in Mainland Portugal. PhD Thesis, Technical University of Lisbon, Portugal; 2007. (In Portuguese).

[21] Lourenço PB, Mendes N., Ramos LF, Oliveira, DV. Analysis of masonry structures without box behaviour. International Journal of Architectural Heritage; 2011 5: 369-382. (doi: 10.1080/15583058.2010.528824). 


\section{List of Figures}

Fig.1 In-plane collapse mechanisms of the piers (adapted from [13]).

Fig.2 In-plane behaviour of the spandrels [14].

Fig.3 Numerical model: (a) general view; (b) detail of the floors.

Fig.4 Envelope of the response obtained from the non-linear dynamic analysis with time integration and capacity curve obtained from the pushover analysis of the reference model in the: (a) transversal direction; (b) longitudinal direction.

Fig.5 Maximum tensile principal strains at the external surface of the non-linear dynamic analyses of the reference model: (a) Earthquake 100\%; (b) Earthquake $300 \%$.

Fig.6 Maximum tensile principal strains at the external surface of the pushover analysis of the reference model in the: (a) transversal direction; (b) longitudinal direction.

Fig.7 Maximum tensile principal strains at the external surface, obtained from the dynamic analysis, varying the Young's modulus of the floors: (a) $0.1 x E_{\text {floors, }}$, ; (b) $10 x E_{\text {floors, ref. }}$

Fig.8 Envelope of the response varying the compressive strength in the: (a) transversal direction; (b) longitudinal direction.

Fig.9 Capacity curves varying the Young's modulus of the timber floors in the: (a) transversal direction; (b) longitudinal direction.

Fig.10 Maximum tensile principal strains at the external surface, obtained from the pushover analysis in the longitudinal direction, varying the Young's modulus of the floors: (a) $0.1 \times E_{\text {floors, ref }}$; (b) $10 x E_{\text {floors, ref. }}$. 


\section{List of Tables}

Table 1 Linear material properties of the reference model.

Table 2 Non-linear material properties of the masonry walls of the reference model.

Table 3 Parameters considered in the in dynamic sensitivity analysis.

Table 4 Variation of the response in the transversal direction obtained from the dynamic sensitivity analysis for the lower limits of the parameters.

Table 5 Variation of the response in the transversal direction obtained from the dynamic sensitivity analysis for the upper limits of the parameters and earthquake vertical component.

Table 6 Parameters considered in pushover sensitivity analysis.

Table 7 Variation of the maximum seismic coefficient obtained from the pushover sensitivity analysis for the lower limits of the parameters.

Table 8 Variation of the maximum seismic coefficient obtained from the pushover sensitivity analysis for the upper limits of the parameters and pushover analysis proportional to the first mode. 